\title{
Evaluation of accuracy of two electronic apex locators of different frequencies in dry and wet condition. (In Vitro Study)
}

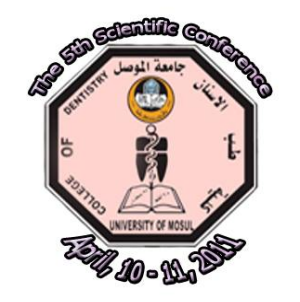

\section{ABSTRACT}

Objective: To evaluate and compare the precision of two electronic apex locators (C-Root I Apex locator III, Guangdong, China \& AFA Apex Finder 7005, Orange, USA) of dual and multi-frequency dependent impedance in dry and wet condition.

Materials and Methods: Twenty-five straight single-rooted teeth with mature apices were used. A flat coronal reference point prepared followed by access preparation and canal widening with Gates Glidden drill. A size $15 \mathrm{~K}$-file introduced inside the canal so that the actual canal length to the major foramen was determined visually under illuminated magnified lens (x5). Teeth were embedded in alginate mold then electronic measurements with two locators of different impedance frequency were made to the apex reading in dry canal condition and with presence of physiologic saline solution using same file. Data was analyzed with ANOVA and T-test $(\alpha=.05)$.

Results: Comparison of apex locators reading show no significant difference between the locators at both conditions of the canal ( $>0.05$ ). No significant differences were found between the actual working length and electronic length for either apex locators ( $p>0.05)$. In contrary both EALs measurements show significantly larger absolute difference in presence of solution than value in dry condition $(\mathrm{p}<0.05)$.

Conclusion: Both apex locators were reliable in

determining the electronic working length of the teeth.

$$
\text { الخلاصة }
$$

ان الهدف من هذه الدر اسة المختبرية هو لتقييم ومقارنة دقة قياس جهازين الكترونيين لتحديد

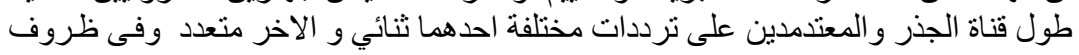

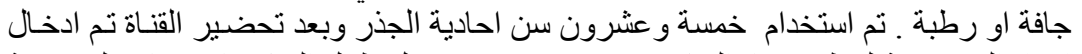

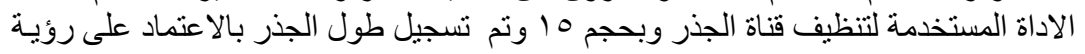

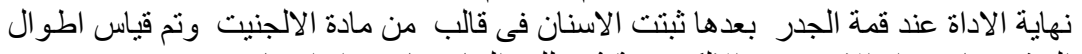

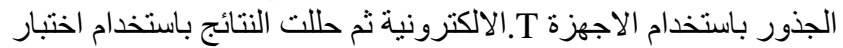

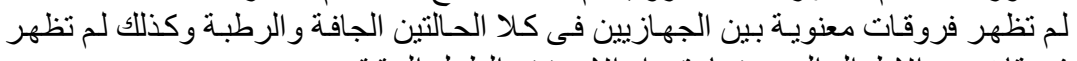

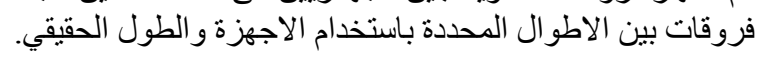

\section{INTRODUCTION}

uccessful root canal therapy depends upon complete and accurate biomechanical preparation followed by a three-dimensional obturation of the root canal system without injuring the periapical tissue. ${ }^{(1)}$ To attain these objectives, the endpoint of the root canal system should be detected carefully prior to preparation of the canal. Although radiography is an important step of endodontic therapy to determine working length, a

Journal of the $5^{\text {th }}$ Scientific Conference of Dentistry College, Apr. 2011 
variety of limitations have been encountered such as inaccurate root canal length result in under or over preparation ${ }^{(2,3)}$ considerable amount of time, and radiation hazard. ${ }^{(4)}$

Since the pioneer studies ${ }^{(5,6)}$ the electronic working length determination has gained considerable popularity among both general dentists and endodontists. Most electronic apex locators EALs were using same principles but the difference between them is basically in the design of the electrical circuits. The current flowed from the device and establish a circuit through the two electrodes attached to the file and another electrode ground in the lip of the patient, current flow back from the circuit to the device that would indicate in the monitor where the file in the canal or it reached the apex. ${ }^{(7)}$

Sunada determined electrical resistance between periodontium and oral mucosa is constant at approximately $6.5 \mathrm{k} \Omega$. On the basis of this concept; resistance-type apex locators were manufactured and introduced into the market but with inaccurate reading in the presence of electrolyte in the canal during measurements. To avoid such problem a development of devices that operate by measuring changes in impedance across the wall of the root canal by applying two different frequencies to a file and measuring the difference between them. ${ }^{(8,9)}$ As a file is advanced apically, the difference in the impedance values begins to become greater and is maximally different at the apical constriction which the file leaves the tooth and enters the periodontium. Further development aim to increase the accuracy by measure the impedance characteristic using more than two frequencies (multifrequency apex locator).

Devices that using different electronic principles (dual and multi-frequencies) may have different ability to determine precision of canal length. Many acquisition being made to electronic apex locators in its accuracy due to shortcoming like existence of fluid that might create the probability of early electric circuit formation before reaching the apex. ${ }^{(10)}$ Therefore the purpose of this study was to evaluate and compare the precision of two electronic apex locators of dual and multi-frequency dependent impedance in dry and wet condition.

\section{MATERIALS AND METHODS}

Twenty-five single-rooted human teeth with mature apices were used. Teeth were cleaned with hand instruments to remove debris and remaining tissues then stored in distilled water at $4 \mathrm{C}^{\circ}$. Pulp chamber were accessed with round bur followed by fissure bur in accelerated speed handpiece with thorough of water spray. Tissues were removed with barbed broach and canals preflared with Gates Glidden drill (Mani Inc., Tochigi, Japan) to facilate file placement. A flat reference point was prepared on the occlusal surface or incisal edge of the teeth to allow for precise positioning of the instrument.

For actual working length measurement a size $15-\mathrm{K}$ file fitted with silicon stop was introduced into the canal until its tip was seen through the apical foramean that was confirmed by viewing with the aid of illuminated magnifier at x5.The silicon stop was stabilized at reference point, the file was removed, and the distance from the stop to the tip was measured with digital caliper and recorded to the nearest $0.01 \mathrm{~mm}$. For electronic apex locator measurements the roots were fixed into freshly mixed alginate inside a plastic container. A stainless steel rod was fixed at the bottom plane of the container and connected to the negative pole of the EALs. The investigated EALs were dual frequency based and multifrequency (C-Root I Apex locator III, Guangdong, China \& AFA Apex Finder 7005, Orange, USA). 
Each locator was used according the manufacturers instruction .Instrument of size $15 \mathrm{~K}$-file was connected to corrosponding locator and gradually introduced inside canal untile the LCD and corresponding acoustic signal indicated that the file had reached the apex when tracking light flashed to red for C-Root or apex for AFA.The measurements were taken up to that mark and noted down. Regarding to the measurements at dry condition the canals were dried with paper points untile no any indication of moisture was observed in point. While for wet condition the canals were irrigated with $2 \mathrm{~mL}$ of $0.9 \% \mathrm{w} / \mathrm{v}$ physiologic saline as an electrolyte at the moment of reading after aspiration of the excess solution from the chamber with cotton pellet. All measurement were performed at random.

Each measurement was repeated three times and mean value computed. For each reading the error in measurement was calculated as absolute difference between the actual length and the electronically measured canal length. The actual canal length measurement for each tooth was subtracted from EAL-derived canal lengths. A positive discrepancy value indicated a longer than actual measurement, i.e., beyond the apical foramen. A negative discrepancy value indicated a shorter than actual measurement. The mean value of the measurements indicated a general tendency of the EALs toward a short or a long reading. Data were analyzed using ANOVA and a student T-test at 95\% confidence level.

\section{RESULTS}

The actual canal length, mean measurements at different canal conditions with standard deviation, and absolute difference are shown in Table 1.The distribution frequencies of the distance between the file tip and the apical foramen are presented in Table 2.

Table 2: Distribution frequency of the distance between the file tip and the apical foramean.

\begin{tabular}{cllllllll} 
& C-Root & & \multicolumn{5}{c}{ AFA } \\
& Dry & & Wet & & Dry & Wet & \\
& $\mathrm{n}$ & $\%$ & $\mathrm{n}$ & $\%$ & $\mathrm{n}$ & $\%$ & $\mathrm{n}$ & $\%$ \\
$0.5-1.0$ & 0 & 0 & 0 & 0 & 0 & 0 & 3 & 12 \\
$0.01-0.5$ & 12 & 48 & 17 & 68 & 8 & 32 & 16 & 64 \\
$-0.5-0.0$ & 13 & 52 & 8 & 32 & 16 & 64 & 6 & 24 \\
$-1.0-(-0.5)$ & 0 & 0 & 0 & 0 & 1 & 4 & 0 & 0 \\
\hline Total & 25 & 100 & 25 & 100 & 25 & 100 & 25 & 100 \\
\hline
\end{tabular}

The result of this study demonstrated that the mean electronic lengths of EALs under dry and wet condition were not significantly different from the actual canal length. Regarding the influence of impedance frequencies of the evaluated EALs on the accuracy of readings the statistical analysis revealed no significant differences between EALs in absolute difference values under both canal conditions ( $p>0.05)$.

On the other hand both apex locators were influenced by canal condition where the result shows a significant difference in the accuracy of measurements $(p<0.05)$, in view of the fact that the mean value of absolute difference when canals filled with physiologic saline was significantly higher than those value in dry condition (Fig.1).

Journal of the $5^{\text {th }}$ Scientific Conference of Dentistry College, Apr. 2011 


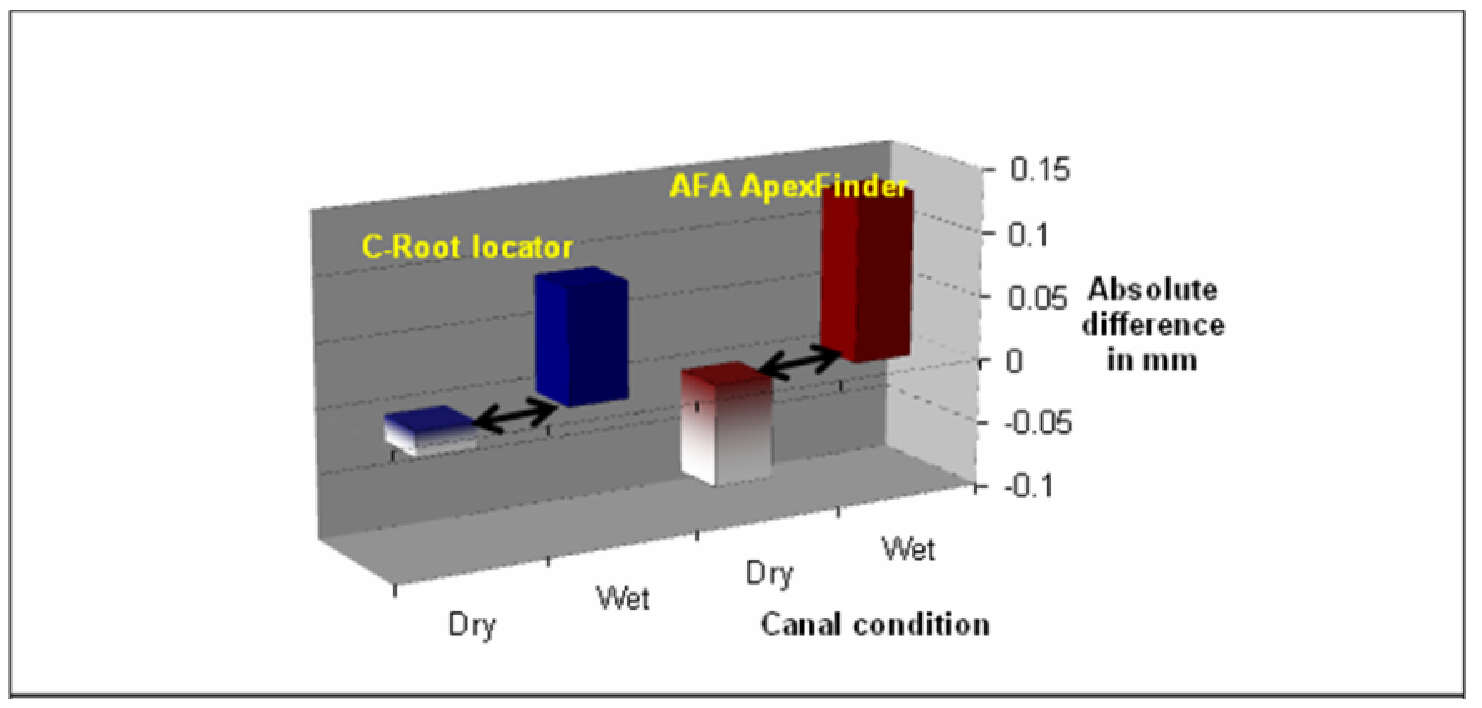

Figure 1. The absolute difference for two apex locators arrows indicate significant difference

Despite the electronic measurements show a tendency towered longer canals length when filled with saline. This deviation of measurements varied according to the type of EAL used. The AFA presenting higher deviation than C-Root, in which the file was surpasses the apex in $12 \%$ of wet cases within the interval between $(0.5-1.0) \mathrm{mm}$ relative to major foramen Table 2. If a tolerance of $\pm 0.5 \mathrm{~mm}$ was allowed the accuracy reached was $100 \%$ for C-Root and $96 \%$ for AFA Apex Finder in dry condition and 88\% in wet condition. Measurement of more than \pm 1.00 was not recorded in this experiment.

\section{DISCUSSION}

In the present study for investigating accuracy of the EALs an ex vivo model have been developed in which extracted teeth were immersed in alginate media. The advantages of this model were their simplicity, ease of use, electroconductive property, simulating the periodontal ligament with its colloidal consistency and electrical resistance. ${ }^{(11)}$ Preflaring of root canals before measurement with EALs can increase the precision of working length determination. ${ }^{(12,13)}$ Thus, the canals were preflared in the current study before measurement.

The actual length employed was that the length as measured by introducing fine file tip until it was just at the level of the apical foramen confirmed by the magnifying lense, which was taken as the 'gold standard'. Some EALs are designed to measure canal lengths at varying distances from the apical foramen, i.e., $0,0.5,1.0 \mathrm{~mm}$, and so on. Usually the major foramen could be used as an apical reference point for laboratory studies. However, in the present study, measurements to the " 0 " mark were taken in order to determine the canal length from coronal reference point to the supposed " 0 " or "Apex" mark, as indicated on the both devices.

It has been reported that when the file reached "Apex" mark the accuracy of EALs were more reliable and reproducible compared with the minor foramean. ${ }^{14,15}$, ${ }^{16)}$ To simulate dry canal condition the evaluation was performed after canal debridement, dryness and before any additional irrigation step. While for wet condition evaluation the root canal was filled with physiologic saline solution followed directly by registration of

Journal of the $5^{\text {th }}$ Scientific Conference of Dentistry College, Apr. 2011 
electronic lengths. Physiologic saline solution of $0.9 \% \mathrm{w} / \mathrm{v} \mathrm{NaCl}$ was selected as electrical conductive media since its ionic content is equivalent to that of blood plasma and biological tissue ${ }^{(17) .}$ In addition previous studies showed that in the presence of saline, measurements were closer to the actual length. ${ }^{(18)}$

Many of the studies used an error range of $\pm 0.5 \mathrm{~mm}$ to assess the accuracy of different frequency dependant EALs and they showed that the accuracy from 90-100\% 19, 20. Measurements attained within this tolerance were considered highly accurate. In comparison to these standards, the accuracy of the present study was $96 \%$ for either locator except in presence of saline within the canal the accuracy of AFA locator was decreased to $80 \%$. It is generally accepted that the minor apical foramen and apical constriction is on average located $0.5-1.0 \mathrm{~mm}$ short of the radiographic apex $(21,22)$. However, many of the root canals do not always end with an apical constriction.

With a lack of such demarcations, an error tolerance up to $\pm 1.0 \mathrm{~mm}$ to the foramen is deemed to the clinically acceptable range of tolerance. ${ }^{(23)}$ Therefore some study rely on more lax clinical range of $\pm 1.0 \mathrm{~mm}$ to the foramen 24 . When $\pm 1.0 \mathrm{~mm}$ tolerance was considered the accuracy of the investigated locators in this study were uprise to $100 \%$ regardless of the canal condition.

Observation of the results reveals a uniformity of measurements, with small standard deviation and very close means, even when compared to the actual root canal sizes (Table 1).

Table 1: Mean of reading values for EALs at dry and wet condition, absolute difference, and the actual canal length.

\begin{tabular}{cccccc} 
& $\begin{array}{c}\text { Actual } \\
\text { Length }\end{array}$ & Dry & C-Root I & \multicolumn{2}{c}{ AFA ApexFinder } \\
& & & & & Dry \\
Mean & 18.53 & 18.50 & 18.62 & 18.45 & 18.66 \\
$(\mathrm{SD})$ & $(0.79)$ & $(0.79)$ & $(0.80)$ & $(0.80)$ & $(0.88)$ \\
& & & & & \\
Absolute & & -0.02 & 0.09 & -0.08 & 0.13 \\
Difference & & & & &
\end{tabular}

The hypothesis to be tested in this study was that whether EALs of similar operating systems but different frequency-dependent (dual and multi-frequency) will present similar results in the same group of teeth. On comparison of the accuracies of the EALs, the result showed no significant differences in the absolute difference between the two types of apex locators. This may indicate that the frequency of the locators have no influence on the accuracy of root canal length regardless of the canal condition dry or wet. There are several studies about the influence of canal irrigants on the accuracy of EALs. Pommer et al. ${ }^{(25)}$ evaluated different irrigants and reported in their study that there was no significant correlation between the values from EALs and the relative moisture in the canal. In the present study both EALs showed a significant difference in the value of absolute difference between the dry canal and in presence of physiologic saline solution, inspite of this difference the mean measurements still had discrepancy values of less than $0.5 \mathrm{~mm}$ in magnitude.

This implies that the devices can be considered reliable when used with saline irrigants, and more accurate without irrigant. Therefore, from the results of the present

Journal of the $5^{\text {th }}$ Scientific Conference of Dentistry College, Apr. 2011 
study, one can deduce that even though the study showed some statistically significant differences between the conditions for devices, they are of little clinical significance. Meredith \& Gulabivala (1997) ${ }^{(26)}$ reported that there was a clear increase in the series resistance with increasing distance from the apex for dry canals (22.19-92.07 kX) and these figures were markedly higher than for those containing deionized water (9.32$12.10 \mathrm{kX})$ and sodium hypochlorite (7.46-8.92 kX).

Measurement of changes in resistance was therefore easier in dry root canals and it is likely that this is why commercial EALs perform better in dry canals in this study.In a previous study the accuracy of the Root ZX apex locator was determined in the presence of saline, and in dry canals ${ }^{27}$.

The results indicated that in the presence of saline, measurements were closer to the actual length, whilst those carried out in dry canals were shorter. The present results that the use of $0.9 \%$ saline adversely affected the measurement sensitivity of the device are in contrast to that of Kaufman et al. ${ }^{27}$. This difference can be explained by the differences in the test conditions (ex vivo and in vivo) and/or also different devices. The result of this in-vitro study needs to be verified in an in- vivo study. Clinically, a higher variation of measurements is expected because in contrast to in-vitro studies favorable circumstances for precise measurements are not available.

\section{CONCLUSION}

Under the condition of the present study the following conclusions can be made particularly from clinical point of view. The difference in frequency impedance didn't influence the accuracy of both EALs. Both EALs are suitable for determining canal working length under dry and wet condition with a tendency to longer measurements with wet canal. It is possible to use them interchangeably without compromising the working length.

\section{REFERENCES}

1. Ricucci D. Apical limit of root canal instrumentation and obturation, part 1. Literature review. Int Endod $J$ 1998; 31(6): 384-33.

2. Stein TJ, Corcoran JF. Zillich RM.J Influence of the major and minor foramen diameters on apical electronic probe measurements. Endod. J 1990 ;16(11):520-2.

3. Martínez-Lozano MA, Forner-Navarro L, Sánchez-Cortés JL, Llena-Puy C Methodological considerations in the determination of working length. Int Endod J. 2001 ;34(5):371-6

4. Pendlebury ME, Horner K, Eaton KA. Selection Criteria for Dental Radiography, 1st ed. London, UK. 2004; p: 6-17.

5. Suzuki K. Experimental study on iontophoresis. Japanese J Stomatol.1942;16, 411-29.

6. Sunada I. New method for measuring the length of the root canal. J Dent Res 1962; 41, 375-87.

7. Nekoofar MH, Ghandi MM, Hayes SJ, Dummer PMH.The fundamental operating principles of electronic rootcanal length measurement devices. Int Endod J 2006;39:595-609.

8. Kobayashi C, Suda H . New electronic canal measuring device based on the ratio method. J Endod ;1994;20,111-4.

9. Kobayashi C. Electronic canal length measurement.Oral Surg, Oral Med, and Oral Path .1995; 79,22631.

10. Trope M, Rabie G, Tronstad L . Accuracy of an electronic apex locator under controlled clinical conditions.Endodont and Dent Traumato.1985; 1, 142-5.

11. Baldi JV, Victorino FR, Bernardes RA, et al. Influence of embedding media on the assessment of electronic apex locators. J Endod 2007;33:476-9.

12. Ibarrola JL, Chapman BL, Howard JH, Knowles KI, Ludlow MO. Effect of preflaring on Root ZX apex locators. J Endod 1999;25, 625-6. 
13.Janolio de Camargo E, Zapata RO, Medeiros PL et al. Influence of preflaring on the accuracy of length determination with four electronic apex locators. J Endod 2009;35, 1300-2.

14.Ounsi H, Naaman A. In vitro evaluation of the reliability of the Root ZX electronic apex locator. Int Endod J 1999;32, 120-3.

15.Lee SJ, Nam KC, Kim YJ, Kim DW. Clinical accuracy of a new apex locator with an automatic compensation circuit. J Endod 2002;28:706-9.

16.Venturi M, Breschi L .A comparison between two electronic apex locators: an ex vivo investigation. Int Endod J .2007;40, 362-73.

17.Pallas-Areny R, Baccetti T. A SEM study of in vivo accuracy of the Root ZX electronic apex locator. $J$ Endod 1998; 40:830-3.

18. Kaufman AY, Keila S, Yoshpe M. Accuracy of a new apex locator: an in vitro study. Int Endod J 2002; 35(2): 186-92.

19. Czerw RJ, Fulkerson MS, Donnelly JC. An in vitro test of a simplified model to demonstrate the operation of electronic root canal measuring devices. J Endod 1994; 20:605-6.

20. De Moor RJG, Hommez GMG, Martens LC, De Boever JG. Accuracy of four electronic apex locators: an in vitro evaluation. Endod Dent Traumatol 1999;15:77-82.

21.Katz A, Tamse A, Kaufman AY .Tooth length determination: a review. Oral Surgery, Oral Medicine, and Oral Pathology 1991;72, 238-42.

22.Morfis A, Sylaras S, Georgopoulou M, Kernani M, Prountzos F. Study of the apices of human permanent teeth with the use of a scanning electron microscope. Oral Surgery, Oral Medicine, and Oral Pathology 1994;77, 172-6.

23. Shabahang S, Goon W, Gluskin A . An in vivo evaluation of Root ZX electronic apex locator. $J$ Endod 1996; 22, 616-8.

24.Keller M, Brown CJ, Newton C. A clinical evaluation of the Endocater - an electronic apex locator. $J$ Endod 1991;17, 271-4.

25.Pommer O, Stamm O, Attin T. Influence of the canal contents on the electrical assisted determination of the length of root canals. J Endod 2002; 28(2):83-5.

26. Meredith N, Gulabivala K. Electrical impedance measurement of root canal length. Endod Dent Traumatol1997; 13, 126-31.

27. Kaufman AY, Keila S, Yoshpe M. Accuracy of a new apex locator: an in vitro study. Int Endod J 2002;35:186-92. 